Research Article

\title{
Thin Film Heater for Removable Volatile Protecting Coatings
}

\begin{abstract}
Abid Karim
Iqra University, Defence View Shaheed-e-Millat Road (Ext.), Karachi 75500, Pakistan

Correspondence should be addressed to Abid Karim; akarimpk@iqra.edu.pk

Received 5 September 2013; Accepted 15 October 2013

Academic Editors: Y.-K. Gao and X. Jia

Copyright ( 2013 Abid Karim. This is an open access article distributed under the Creative Commons Attribution License, which permits unrestricted use, distribution, and reproduction in any medium, provided the original work is properly cited.

Freshly coated aluminum mirrors have excellent reflectivity at far ultraviolet wavelengths. However, reflectivity rapidly degrades when the mirror surfaces are exposed to atmosphere. In order to avoid this problem, freshly coated aluminum surface can be protected by over-coating of a removable volatile protecting coating. This protecting coating can be re-evaporated by controlled heating or by some other methods when required. This type of removable coating has immediate application in UV space astronomy. The purpose of this paper is to demonstrate the feasibility of re-evaporation of removable volatile $\mathrm{Zn}$ protecting coating using a $\mathrm{NiCr}$ thin film heater without affecting the reflection properties of Al mirror surfaces.
\end{abstract}

\section{Introduction}

There is a considerable interest in the development of reflecting optical coating for space-borne experiments in UV astronomy in the wavelength region of $80 \mathrm{~nm}$ to $120 \mathrm{~nm}$ [1]. For technological reasons, however, this is a very difficult region of the spectrum to explore. The main problem is that the normal-incidence reflectors are very inefficient and at present, only fresh evaporated aluminum is the only known material in this region of electromagnetic radiation spectrum. Unparalleled reflectance of $\mathrm{Al}$ in far ultraviolet (FUV) region degrades when $\mathrm{Al}$ is exposed to normal atmosphere or even to the residual atmosphere of an ultrahigh vacuum system. Alternatively other materials such as thin films of $\mathrm{SiC}, \mathrm{B}_{4} \mathrm{C}$, and Ir are used. But they have low reflectance (20\%-50\%). The standard mirror technology is to use aluminum films over-coated with nonabsorbing thin protective layer of $\mathrm{MgF}_{2}$ or LiF (which prevent oxidation above $115 \mathrm{~nm}$ and $105 \mathrm{~nm}$, resp.) $[2,3]$. However, both materials absorb very strongly at shorter wavelengths as they become opaque below their cutoff wavelengths. Hamza et al. [4] and Méndez et al. [5] have investigated the reflection properties of $\mathrm{Al}$ surfaces over-coated with thin protected layers of $\mathrm{C}_{60}$ and $\mathrm{C}_{70}$ films. Although their results show the lowering of cutoff wavelength by the use of $\mathrm{C}_{60}$ and $\mathrm{C}_{70}$ over-coatings, reflectance of mirror surfaces was less than that of freshly evaporated Al mirrors. Bates [1] proposed in situ preparation of $\mathrm{Al}$ thin films mirrors within the orbiting satellite because it is well-established fact that the space environment of a geosynchronous satellite is not expected to cause serious degradation of pure $\mathrm{Al}$ mirror surfaces. However, there is no established technique for preparing such aluminum thin film mirror surfaces in an orbiting satellite. An alternative technique has been proposed by Burton [6]. In this proposed technique, a freshly coated pure $\mathrm{Al}$ mirror surface would immediately be over-coated with a thin volatile protective film in a ground-based laboratory to avoid oxidation of the aluminum mirror. After the launch of satellite, the volatile protecting film would be removed using a suitable technique including ion bombardment, controlled heating, and plasma etching to obtain the clean and original $\mathrm{Al}$ mirror surface. Controlled heating can simply be carried out by including a resistive thin film (i.e., thin film heater) below the composite coated surface (a surface coated with $\mathrm{Al}$ mirror and volatile protective coating of $\mathrm{Zn}$ ). The concept of re-evaporation of volatile protecting coating in the geostationary orbital space environment is described as REVAP coating. In this paper, $\mathrm{NiCr}$ thin film heater for re-evaporation of $\mathrm{Zn}$ protecting coating is designed. Results show the feasibility of using this type of thin film heating element for REVAP coatings. 


\section{Design Considerations}

2.1. Optimum Design of Heater. There are two commonly used configurations for the fabrication of thin film heaters. These are [7]:

(i) straight line track,

(ii) meandering track.

In the case of straight line track, due to low resistance (as a result of higher width), current through the track is very difficult to control because it increases rapidly with nominal increase in the thickness of thin film [8]. Whereas, due to ease of control of current through the track and stability of film, a meandering track is found to be superior than that of straight line track for the design of a heater. Therefore, meandering track design was used as an optimum design for thin film heater.

2.2. Material for Heater. Throughout the work reported in this paper, $\mathrm{NiCr}$ has been used for the fabrication of thin film heater on top of a circular glass substrate since $\mathrm{NiCr}$ is a widely used material for the fabrication of thin film resistor to be used at high temperatures with high reliability [9]. Due to poor contact making ability of $\mathrm{NiCr}$, gold was deposited at both ends of a track for electrical contacts when and wherever necessary.

2.3. Selection of Material for REVAP Protecting Coating. The requirements for protecting coating materials are as follows.

(1) It should be able to protect and not to degrade the reflectivity of clean $\mathrm{Al}$ mirror surfaces.

(2) It should have low evaporating and re-evaporating temperatures.

(3) It should be thick enough to stop penetration of water vapors, oxygen, and other possible contaminants through the film and reacting with $\mathrm{Al}$.

(4) It has to be stable.

(5) Its growth should be smooth without pinhole to avoid oxidation of $\mathrm{Al}$.

All these conditions are difficult to meet. However, various inorganic compounds, metals, and some organic substances are the possible targets. A material that either has reasonably high reflectivity or has good transparency in the required spectral region can only be considered for protecting coating because these properties can be used for in situ alignment purposes. These criteria suggest that cadmium and zinc are the suitable materials. Due to toxic properties of $\mathrm{Cd}, \mathrm{Zn}$ was selected as the material for REVAP protecting coating for the work presented in this paper.

2.4. Thickness Measurement. All film layers were grown by evaporation of the required material at very high vacuum $\left(10^{-5}\right.$ torr or better) on a circular glass substrate. It was insured that all films were very smooth. Transmission of each film was measured in situ by comparing intensity of incoming

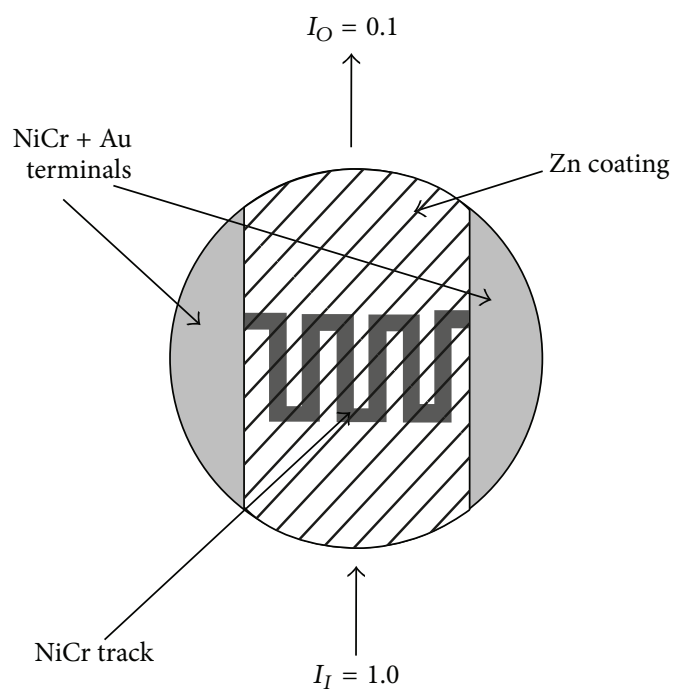

FIGURE 1: Zn coating on top of a glass plate. Meandering tack is covering a small area of glass plate.

radiation $I_{I}$ and intensity of transmitted radiation, $I_{O}$ using a detector and a white light source. Thickness $t$ of the film was calculated by relating it to optical transmission, $T$ via [8]:

$$
T=1+\frac{A_{F}}{A_{G}}\left(e^{-\mu t}-1\right),
$$

where $A_{F}$ is the film area. $A_{G}$ is the area of glass substrate and $\mu$ can be calculated as [8]

$$
\mu=-\frac{\ln T}{t} .
$$

\section{Experimental Techniques and Results}

A NiCr meandering track was deposited on a circular glass substrate. This track was covering only the central part of the circular glass substrate. Gold contacts were deposited at both ends of this track. A layer of $\mathrm{Zn}$ with $10 \%$ transmission was deposited on top of the NiCr meandering track in such a way that it has covered the whole substrate except the gold contact area as shown in Figure 1.

After the deposition of the $\mathrm{Zn}$ coating on the top of $\mathrm{NiCr}$ meandering track, electric current was applied in a high vacuum $\left(10^{-5}\right.$ torr $)$, so that it can be used as a heater. Current was gradually increased to a maximum value where the total power dissipation was $1.5 \mathrm{~W}$. At the same time, optical transmission through the $\mathrm{Zn}$ coated plate was monitored continuously. As the power was increased due to increase in current through the track, temperature was increased. As the track was gradually heated up, a change in the response of detector was observed, indicating that the re-evaporation of the $\mathrm{Zn}$ coating was taking place. Change in optical transmission as a function of the time was watched carefully. Data obtained during the deposition and re-evaporation process is plotted in Figure 2. 


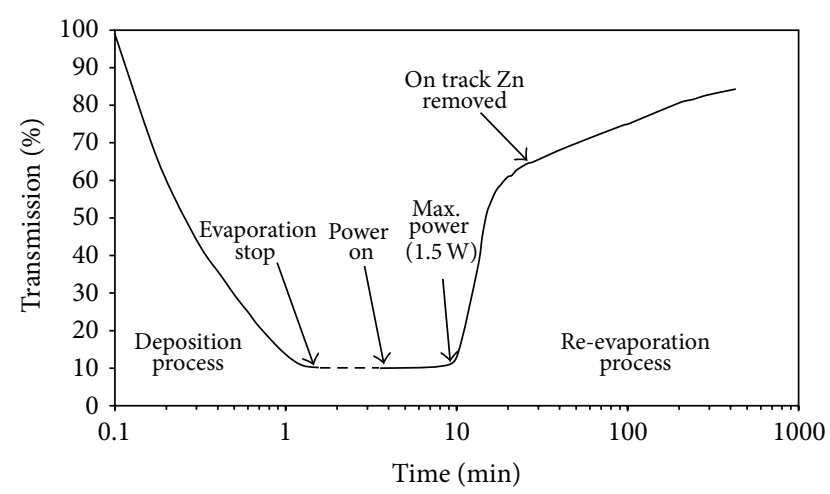

FIgURE 2: Deposition and re-evaporation process as a function of time. Meandering track is covering a small portion of $\mathrm{Zn}$ coated area.

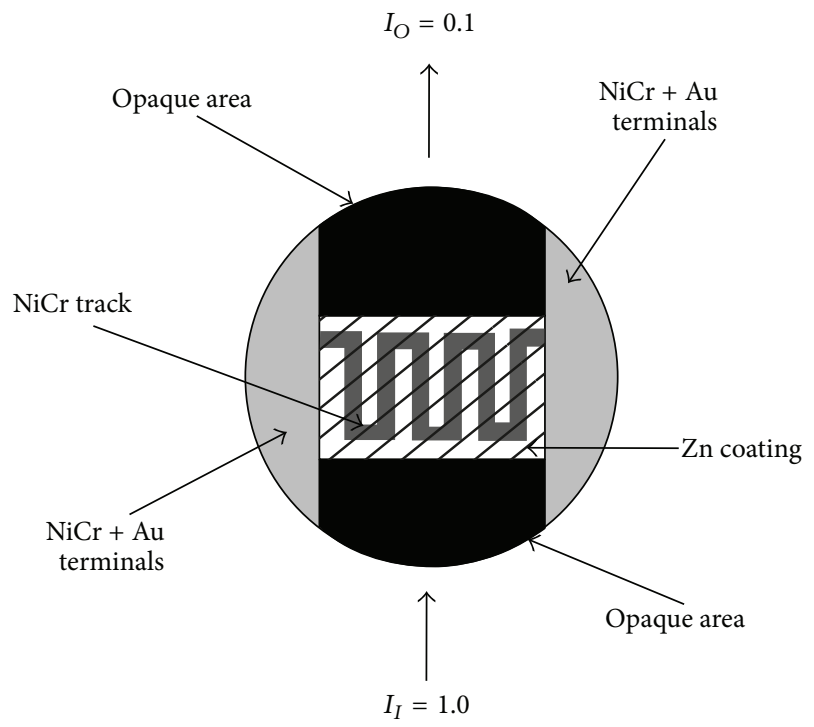

FIgURE 3: $\mathrm{Zn}$ coating on top of a glass plate. Meandering tack is covering a larger portion of $\mathrm{Zn}$ coated area.

It can be seen from Figure 2 that around $60 \%$ transmission was achieved very quickly and the maximum transmission of around $85 \%$ could only be achieved after a long time. The reason behind this behavior was that the meandering track (which was used as a heating element) was covering some area of the circular glass disc and the remaining area was without $\mathrm{NiCr}$ heater whereas $\mathrm{Zn}$ coating was deposited over the whole plate (except the gold contact areas). $\mathrm{Zn}$ coating close to the track re-evaporated very quickly, but the part of $\mathrm{Zn}$ coating which was away from the meandering track re-evaporated slowly due to temperature gradient between the glass plate and the heating track. This type of behavior suggests that the $\mathrm{Zn}$ could have been reevaporated very quickly if it would have been deposited in the close vicinity of the track. Therefore, evaporation and reevaporating process was repeated by depositing $\mathrm{Zn}$ coating only on the meandering track (as shown in Figure 3).

Results obtained for this sample are plotted in Figure 4. As it can be seen from Figure 4, around 98\% of transmission

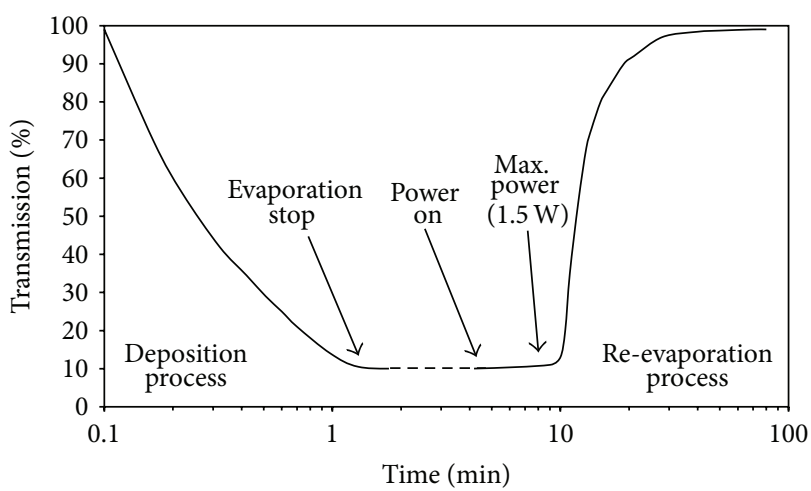

FIGURE 4: Deposition and re-evaporation process as a function of time. Meandering tack is covering a larger portion of $\mathrm{Zn}$ coated area.

was achieved quickly as compared with results of Figure 2. These results ultimately suggest that the $\mathrm{Zn}$ coated $\mathrm{Al}$ mirrors should contain $\mathrm{NiCr}$ under layer on whole glass surface.

\section{Conclusions}

Basic experiments carried out during the work presented in this paper show the feasibility of using zinc protected aluminum mirror surfaces in space-borne UV astronomical applications. From the experimental observation, it can be concluded that in order to perform REVAP phenomena at low temperature, the vacuum should be as high as possible because the temperature required to cause re-evaporation would increase with the increase in air pressure.

\section{References}

[1] B. P. Bates, "Lyman - a future ultraviolet spectroscopic observatory?” The Irish Astronomical Journal, vol. 17, pp. 457-461, 1986.

[2] J. I. Larruquert and R. A. Keski-Kuha, "Removal of a protective coating on $\mathrm{Al}$ by ion etching for high reflectance in the far ultraviolet," Applied Optics, vol. 47, no. 29, pp. 5253-5260, 2008.

[3] M. Fernández-Perea, J. I. Larruquert, J. A. Aznárez, A. Pons, and J. A. Méndez, "Vacuum ultraviolet coatings of Al protected with $\mathrm{MgF}_{2}$ prepared both by ion-beam sputtering and by evaporation," Applied Optics, vol. 46, no. 22, pp. 4871-4878, 2007.

[4] A. V. Hamza, J. Dykes, W. D. Mosley, L. Dinh, and M. Balooch, "Reaction and passivation of aluminum with $\mathrm{C}_{60}$ " Surface Science, vol. 318, no. 3, pp. 368-378, 1994.

[5] J. A. Méndez, J. I. Larruquert, and J. A. Aznarez, "Preservation of far-UV aluminum reflectance by means of overcoating with $\mathrm{C}_{60}$ films," Applied Optics, vol. 39, no. 1, p. 149, 2000.

[6] W. M. Burton, "Removable volatile protective coatings for aluminised mirrors used in far-ultraviolet space astronomy," Journal of Physics D, vol. 16, no. 7, p. L129, 1983.

[7] R. W. Berry, P. M. Hall, and M. T. Harris, Thin Film Technology, D. Van Nostrand, Princeton, NJ, USA, 1968.

[8] A. Karim, Properties and applications of vacuum deposited metal coatings [M.S. thesis], Queens University of Belfast, 1988.

[9] A. Peled, J. Farhady, Y. Zloof, and V. Baranauskas, “The midrange and high temperature dependence of vacuum deposited NiCr thin film resistors," Vacuum, vol. 45, no. 1, p. 5, 1994. 

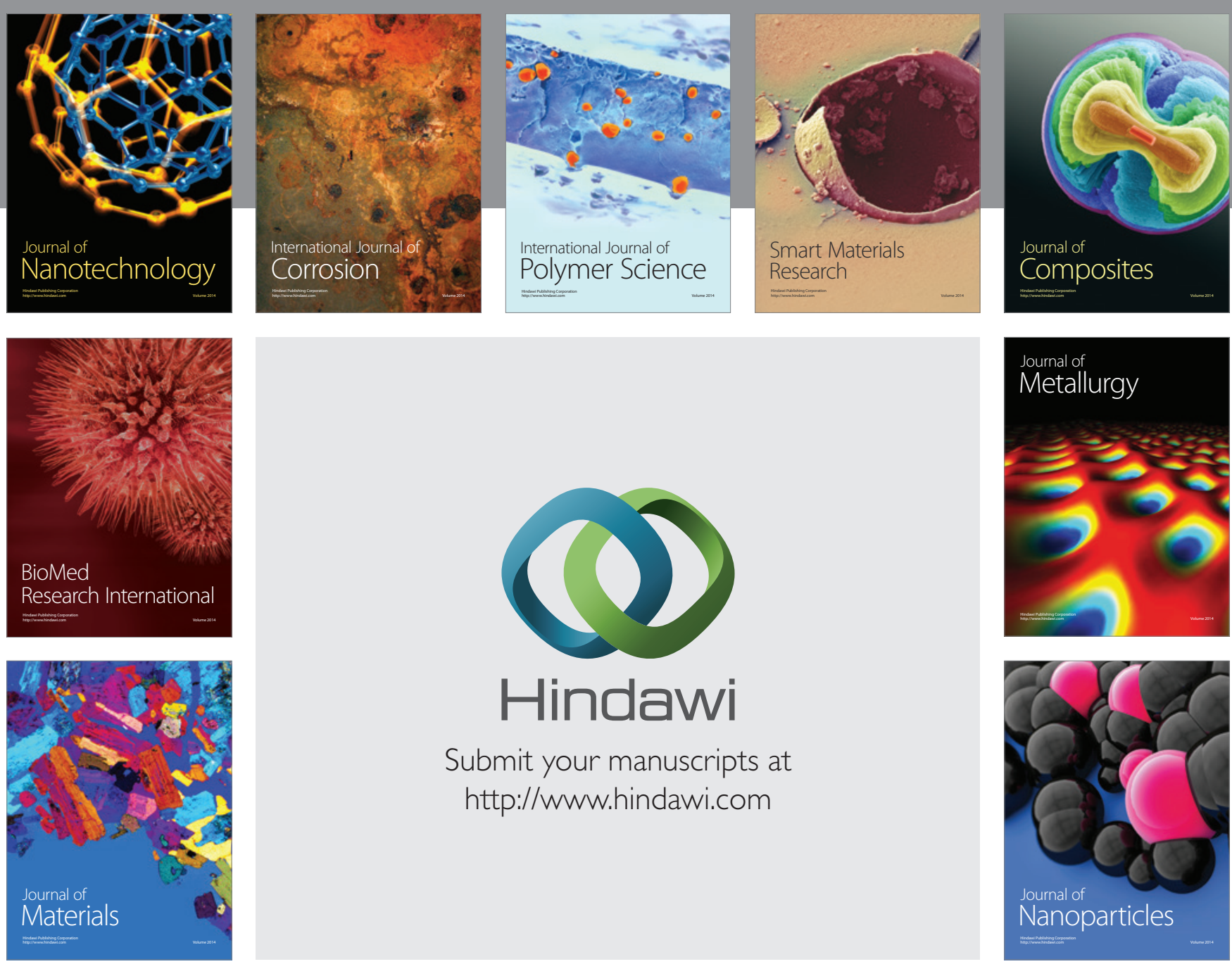

Submit your manuscripts at http://www.hindawi.com
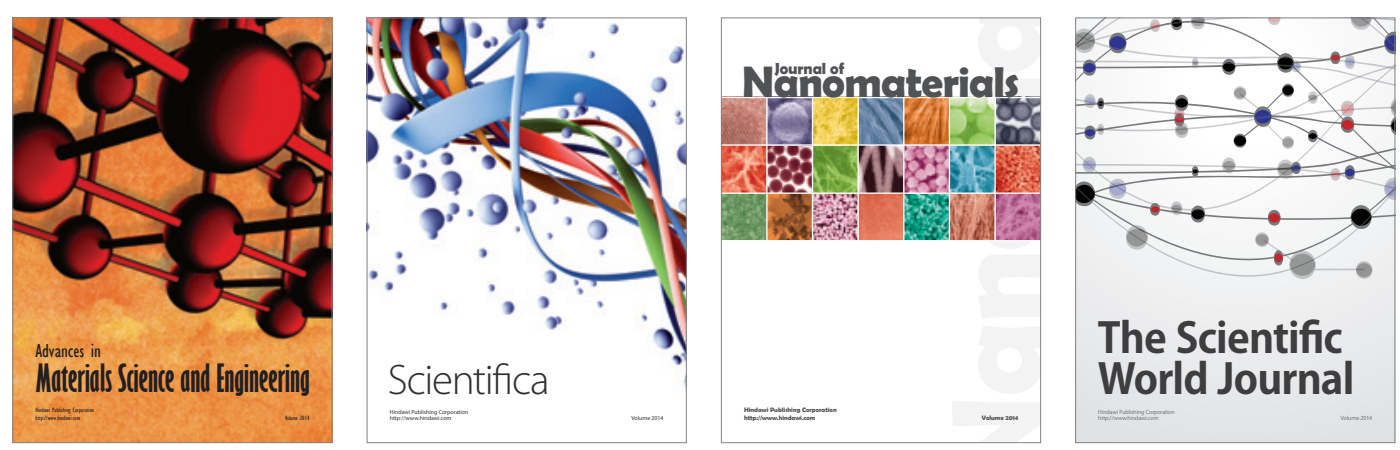

\section{The Scientific World Journal}
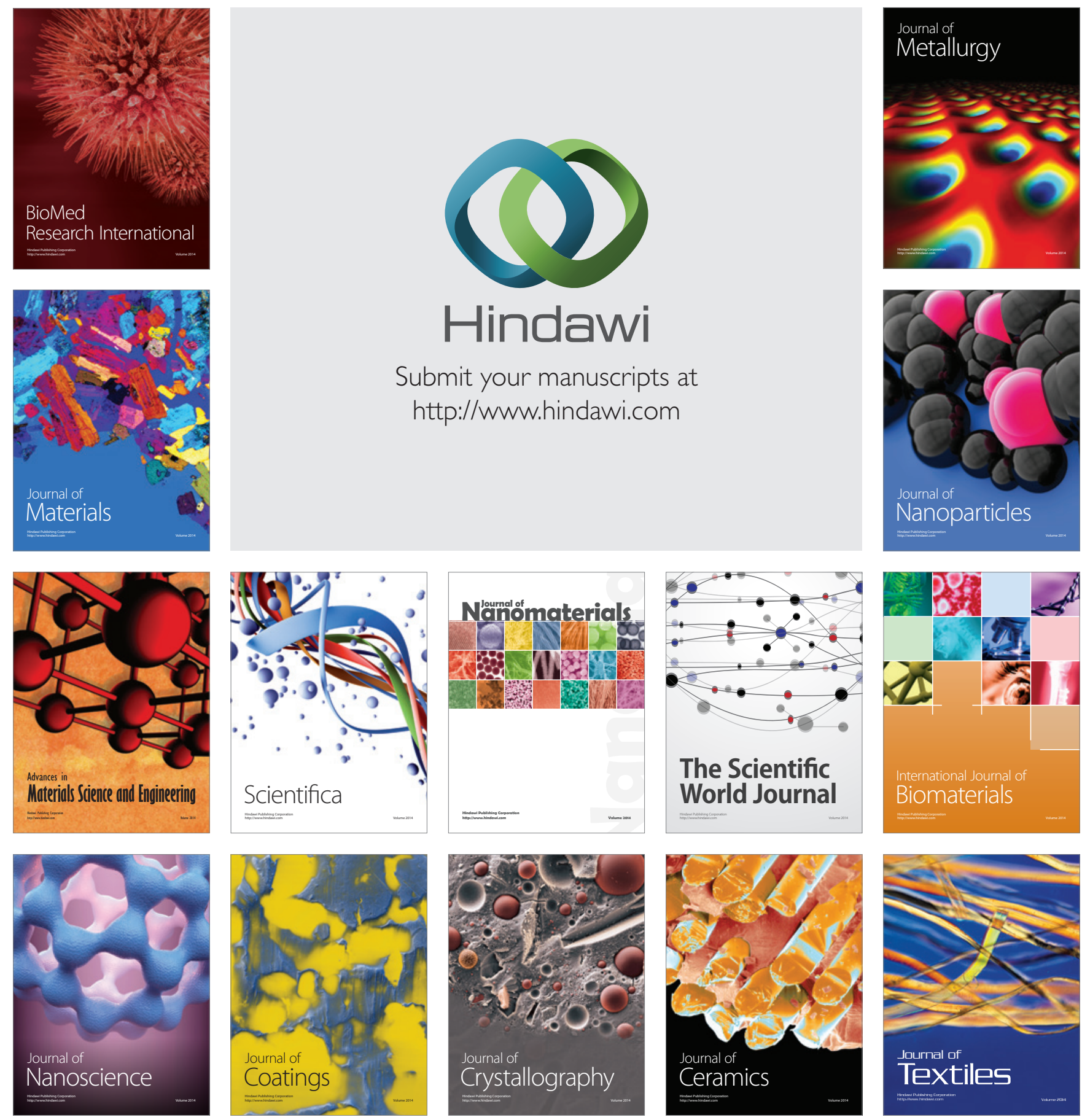